\title{
Reversible brain atrophy and cognitive impairment in an adolescent Japanese patient with primary adrenal Cushing's syndrome
}

This article was published in the following Dove Press journal:

Neuropsychiatric Disease and Treatment

I5 September 2014

Number of times this article has been viewed

\author{
Nobumasa Ohara' \\ Hiroshi Suzuki' \\ Akiko Suzuki' \\ Masanori Kaneko' \\ Masahiro Ishizawa' \\ Kazuo Furukawa' \\ Takahiro Abe ${ }^{\prime}$ \\ Yasuhiro Matsubayashi' \\ Takaho Yamada' \\ Osamu Hanyu' \\ Takayoshi Shimohata ${ }^{2}$ \\ Hirohito Sone' \\ 'Department of Hematology, \\ Endocrinology and Metabolism, \\ Faculty of Medicine, Niigata \\ University, Niigata, Japan; \\ ${ }^{2}$ Department of Neurology, Brain \\ Research Institute, Niigata University, \\ Niigata, Japan
}

Correspondence: Nobumasa Ohara Department of Hematology,

Endocrinology and Metabolism, Faculty of Medicine, Niigata University, I-757 Asahimachi-dori, Chuo-ku, Niigata 95|-85I0, Japan

$\mathrm{Tel}+8 \mathrm{I} 253689026$

Fax +8I 253689300

Email oharan@med.niigata-u.ac.jp

\begin{abstract}
Endogenous Cushing's syndrome is an endocrine disease resulting from chronic exposure to excessive glucocorticoids produced in the adrenal cortex. Although the ultimate outcome remains uncertain, functional and morphological brain changes are not uncommon in patients with this syndrome, and generally persist even after resolution of hypercortisolemia. We present an adolescent patient with Cushing's syndrome who exhibited cognitive impairment with brain atrophy. A 19-year-old Japanese male visited a local hospital following 5 days of behavioral abnormalities, such as money wasting or nighttime wandering. He had hypertension and a 1-year history of a rounded face. Magnetic resonance imaging (MRI) revealed apparently diffuse brain atrophy. Because of high random plasma cortisol levels $(28.7 \mu \mathrm{g} / \mathrm{dL})$ at $10 \mathrm{AM}$, he was referred to our hospital in August 2011. Endocrinological testing showed adrenocorticotropic hormoneindependent hypercortisolemia, and abdominal computed tomography demonstrated a $2.7 \mathrm{~cm}$ tumor in the left adrenal gland. The patient underwent left adrenalectomy in September 2011, and the diagnosis of cortisol-secreting adenoma was confirmed histologically. His hypertension and Cushingoid features regressed. Behavioral abnormalities were no longer observed, and he was classified as cured of his cognitive disturbance caused by Cushing's syndrome in February 2012. MRI performed 8 months after surgery revealed reversal of brain atrophy, and his subsequent course has been uneventful. In summary, the young age at onset and the short duration of Cushing's syndrome probably contributed to the rapid recovery of both cognitive dysfunction and brain atrophy in our patient. Cushing's syndrome should be considered as a possible etiological factor in patients with cognitive impairment and brain atrophy that is atypical for their age.
\end{abstract}

Keywords: Cushing's syndrome, brain atrophy, cognitive impairment, adrenalectomy, adolescent

\section{Introduction}

Endogenous Cushing's syndrome is an endocrine disease resulting from chronic exposure to excessive glucocorticoids produced in the adrenal cortex. ${ }^{1}$ Adrenocorticotropic hormone (ACTH)-secreting tumors, mainly of pituitary origin (Cushing's disease), are the most common form of endogenous Cushing's syndrome, and cortisolsecreting adrenal tumors are responsible for approximately $20 \%$ of cases of this syndrome in Western populations and for $40 \%$ in the Japanese population. ${ }^{2,3}$

Although endogenous or exogenous Cushing's syndrome produces a variety of physical clinical features, such as truncal obesity, thin skin, easy bruising, proximal weakness, osteopenia, gonadal dysfunction, hypertension, and glucose intolerance, it also affects the central nervous system. Studies have shown that many patients with Cushing's syndrome present with cognitive or psychological alterations. ${ }^{1,2,4}$ Furthermore, several studies confirmed the occurrence of diffuse brain atrophy associated with cognitive impairment in both children and adults with all types of Cushing's syndrome. ${ }^{5-9}$ 
Although the ultimate outcomes remain uncertain, these central nervous system alterations persist over several years even after resolution of hypercortisolemia ${ }^{10,11}$ and contribute to long-term impairment in quality of life. ${ }^{12}$ Here, we report a case of cognitive dysfunction with brain atrophy in an adolescent patient with Cushing's syndrome.

\section{Case report}

A 19-year-old Japanese male visited a local general hospital in July 2011 after 5 days of behavioral abnormalities, such as money wasting or nighttime wandering. His family history was unremarkable. He had never consumed alcohol or smoked cigarettes. He had been healthy until the appearance of a rounded face 12 months prior to the visit, and 9 months later he was found to have hypertension upon routine medical checkup. He developed insomnia, a short temper, and restlessness 1 month before the visit. Magnetic resonance imaging (MRI) of the brain revealed no focal lesions but diffuse brain atrophy, including in the cerebrum, cerebellum, and hippocampus (Figure 1, A-C). Because the laboratory examination showed hypokalemia and high random plasma cortisol levels $(28.7 \mu \mathrm{g} / \mathrm{dL})$ at $10 \mathrm{AM}$, he was referred to our hospital for further endocrine function evaluation in August 2011.

His consciousness was clear, but he presented with disorientation, planotopokinesia, and impaired reality-testing, with a global assessment of functioning score of 38 out of 100 using the Reintegration to Normal Living Index. ${ }^{13}$ His height and weight were $168.8 \mathrm{~cm}$ and $56.3 \mathrm{~kg}$, respectively. His blood pressure and pulse rate were $175 / 105 \mathrm{mmHg}$ and 63 beats per minute, respectively, under antihypertensive treatment with olmesartan $20 \mathrm{mg} /$ day. No chest rales or heart murmurs were detected. He exhibited a rounded face, thin skin, easy bruising, purple skin striae on the bilateral buttocks, and mild peripheral edema. Laboratory findings showed ACTH-independent hypercortisolemia and hypokalemia while under oral administration of $1,800 \mathrm{mg}$ /day potassium chloride (Table 1 ). A circadian rhythm in plasma cortisol levels was absent, and plasma ACTH was undetectable. An oral dose of dexamethasone (1 mg) at 11 PM did not suppress plasma cortisol levels $(25.5 \mu \mathrm{g} / \mathrm{dL})$ the following morning. Abdominal computed tomography demonstrated a left adrenal tumor, and ${ }^{131} \mathrm{I}$-adosterol scan revealed marked uptake on the same side (Figure 2),
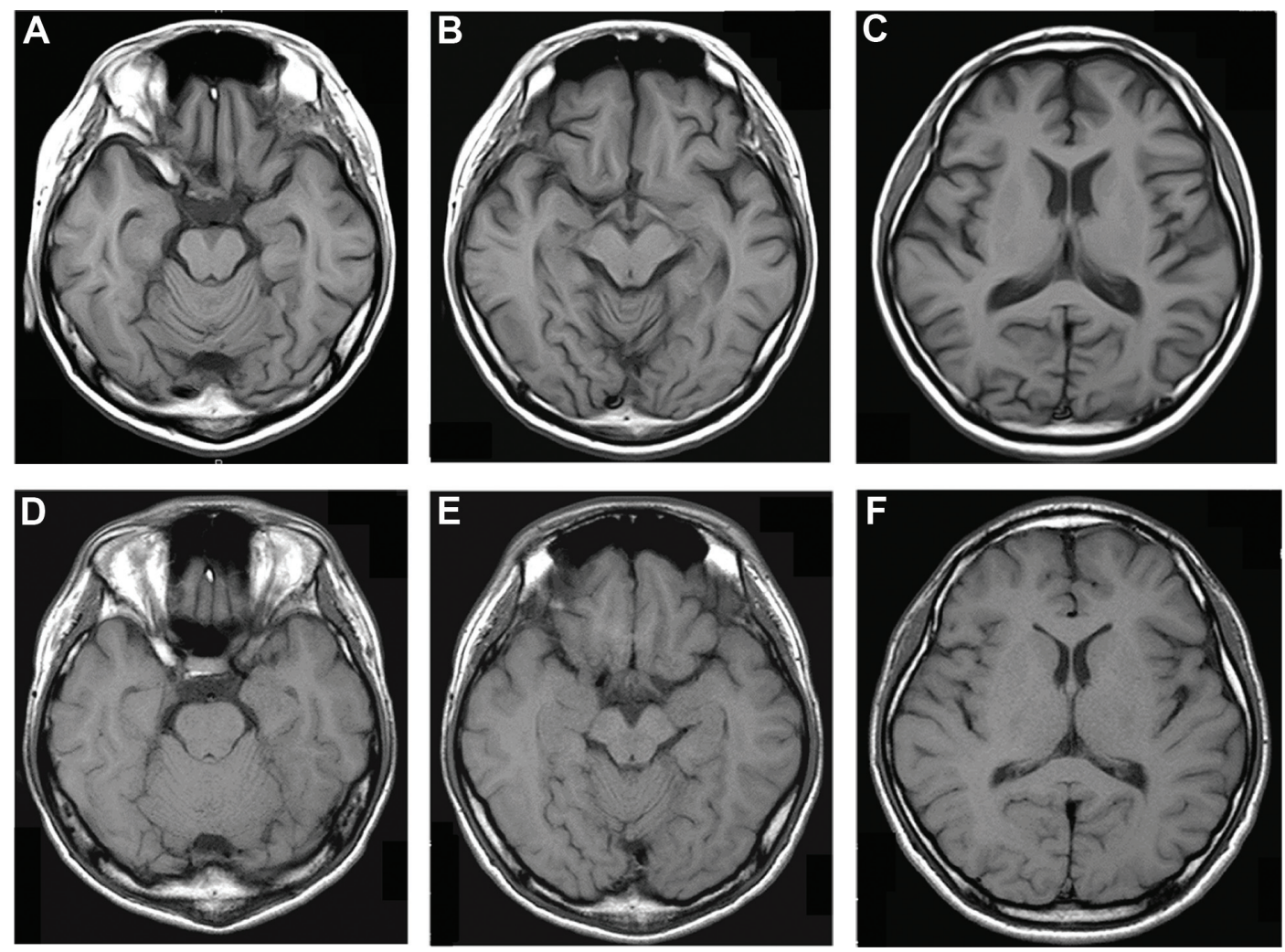

Figure I Transverse TI-weighted magnetic resonance images of the brain.

Notes: (A-C) Diffuse atrophy of the brain, including the cerebrum, cerebellum, and hippocampus was found, accompanied by dilatation of ventricles, subarachnoid space, and sulci, with an Evans' index of 0.25 . (D-F) Eight months after surgical removal of cortisol-secreting adrenocortical adenoma, brain atrophy recovered. Dilatation of ventricles, subarachnoid space, and sulci was also resolved, with an Evans' index of 0.22 . 
Table I Laboratory findings in August 20I I

\begin{tabular}{|c|c|}
\hline \multicolumn{2}{|l|}{ Hematology } \\
\hline White blood cells & $10,250 / \mathrm{mm}^{3}$ \\
\hline Red blood cells & $422 \times 10^{4} / \mu \mathrm{L}$ \\
\hline Hemoglobin & $13.3 \mathrm{~g} / \mathrm{dL}$ \\
\hline Hematocrit & $38.8 \%$ \\
\hline Platelets & $18.8 \times 10^{4} / \mathrm{mm}^{3}$ \\
\hline \multicolumn{2}{|l|}{ Chemistry } \\
\hline Total protein & $6.3 \mathrm{~g} / \mathrm{dL}$ \\
\hline Albumin & $4.1 \mathrm{~g} / \mathrm{dL}$ \\
\hline Aspartate aminotransferase & $27 \mathrm{IU} / \mathrm{L}$ \\
\hline Alanine aminotransferase & $30 \mathrm{IU} / \mathrm{L}$ \\
\hline Gamma-glutamyl transpeptidase & 36 IU/L \\
\hline Urea nitrogen & $13 \mathrm{mg} / \mathrm{dL}$ \\
\hline Creatinine & $0.73 \mathrm{mg} / \mathrm{dL}$ \\
\hline Sodium & $145 \mathrm{mmol} / \mathrm{L}$ \\
\hline Potassium & $2.7 \mathrm{mmol} / \mathrm{L}$ \\
\hline Chloride & $104 \mathrm{mmol} / \mathrm{L}$ \\
\hline C-reactive protein & $0.01 \mathrm{mg} / \mathrm{dL}$ \\
\hline Fasting plasma glucose & $4.9 \mathrm{mmol} / \mathrm{L}$ \\
\hline Hemoglobin $\mathrm{A}_{\mathrm{Ic}}$ & $5.2 \%$ \\
\hline \multicolumn{2}{|l|}{ Urine analysis } \\
\hline Specific gravity & 1.009 \\
\hline Glucose & - \\
\hline Protein & - \\
\hline Occult blood reaction & - \\
\hline Ketone body & - \\
\hline \multicolumn{2}{|l|}{ Endocrinological examination } \\
\hline Plasma aldosterone & $6.3 \mathrm{ng} / \mathrm{dL}$ \\
\hline Plasma renin activity & $2.0 \mathrm{mg} / \mathrm{dL} / \mathrm{h}$ \\
\hline Serum DHEA-S & 294 ng/mL $(240-5,370)^{\#}$ \\
\hline \multicolumn{2}{|l|}{ Plasma cortisol } \\
\hline $8 \mathrm{AM}$ & $29.1 \mu \mathrm{g} / \mathrm{dL}$ \\
\hline $4 \mathrm{PM}$ & $26.2 \mu \mathrm{g} / \mathrm{dL}$ \\
\hline 12 PM & $26.4 \mu \mathrm{g} / \mathrm{dL}$ \\
\hline \multicolumn{2}{|l|}{ Plasma ACTH } \\
\hline $8 \mathrm{AM}$ & $<\mathrm{I} .0 \mathrm{pg} / \mathrm{mL}$ \\
\hline $4 \mathrm{PM}$ & $<1.0 \mathrm{pg} / \mathrm{mL}$ \\
\hline $12 \mathrm{PM}$ & $<\mathrm{I} .0 \mathrm{pg} / \mathrm{mL}$ \\
\hline Urinary free cortisol & $\mathrm{I}, 280 \mu \mathrm{g} / \mathrm{day}$ \\
\hline
\end{tabular}

Note: "Reference range.

Abbreviations: ACTH, adrenocorticotropic hormone; DHEA-S, dehydroepiandrosterone sulfate. suggesting a diagnosis of primary adrenal Cushing's syndrome. His hypertension was treated with a combination of amlodipine (10 mg/day) and olmesartan (40 mg/day). Upon presentation to the psychiatric service, he was considered to have cognitive disturbance possibly due to Cushing's syndrome, and was followed up closely without therapy.

Laparoscopic left adrenalectomy was performed in September 2011. Microscopic examination was consistent with a benign cortisol-secreting adrenocortical adenoma (Figure 3). Following surgery, intravenous administration of hydrocortisone was initiated, and then oral hydrocortisone $(20 \mathrm{mg} /$ day) was maintained. His peak plasma levels of ACTH and cortisol after intravenous corticotropin-releasing hormone ( $1 \mathrm{mg}$ ) were $5.2 \mathrm{pg} / \mathrm{mL}$ (at 30 minutes) and $0.3 \mu \mathrm{g} / \mathrm{dL}$ (at 60 minutes), respectively, under maintenance replacement therapy 2 weeks after surgery.

His postoperative course was uncomplicated, and his blood pressure levels and serum potassium concentration normalized without the need for medication. Behavioral abnormalities were no longer observed after surgery, and he was finally classified as cured of his cognitive disturbance caused by Cushing's syndrome at the psychiatric service in February 2012. The Cushingoid features disappeared, and MRI of the brain performed 8 months after surgery revealed recovery of the brain volume (Figure 1, D-F). The dilatation of ventricles, subarachnoid space, and sulci were also resolved, and scores for estimating ventricular volume were reduced from 0.25 to 0.22 according to the Evans' index. ${ }^{14}$ Thirty months after surgery, his right adrenal function was found to have normalized, and the replacement therapy was discontinued. His mental status improved markedly, with a Reintegration to Normal Living Index of 92 out of 100.
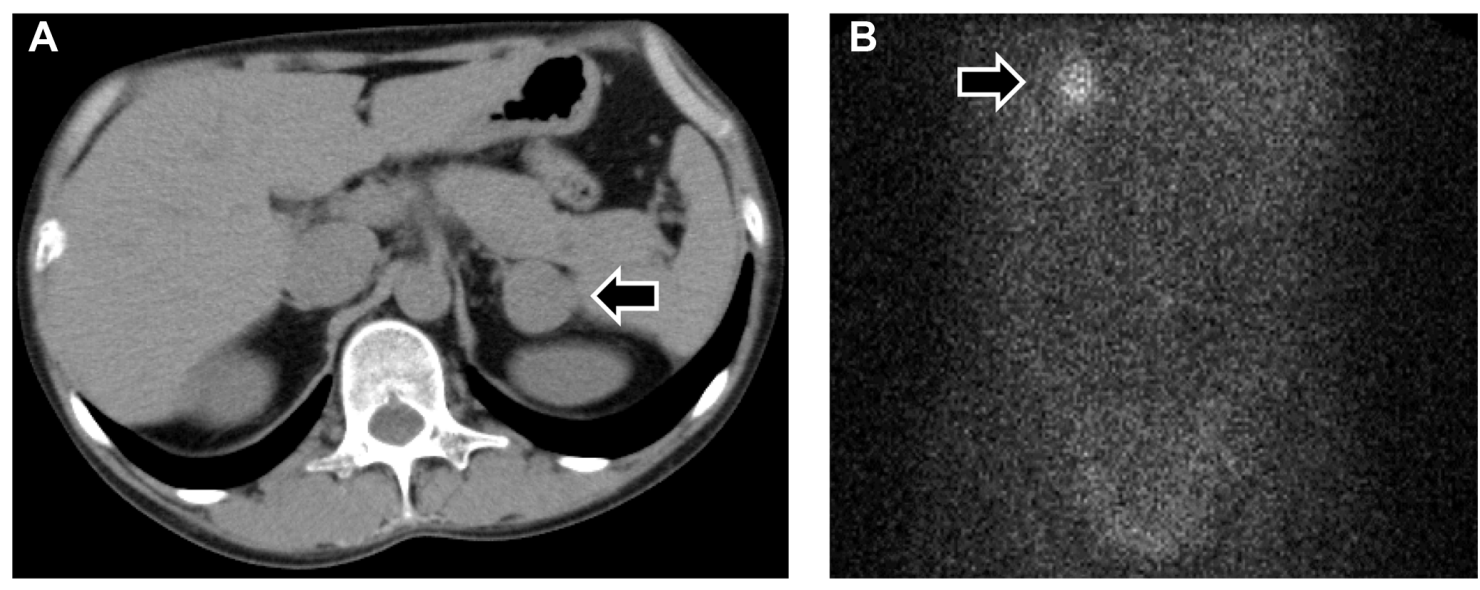

Figure 2 Radiological findings.

Notes: (A) Plain abdominal computed tomography showed a tumor of $2.7 \mathrm{~cm}$ diameter with 35 Hounsfield units (arrow) in the left adrenal gland. (B) ${ }^{131}$ I-adosterol scan (posterior view) demonstrated radioisotope accumulation in accordance with the left adrenal mass (arrow), while no uptake was detected on the opposite side. 

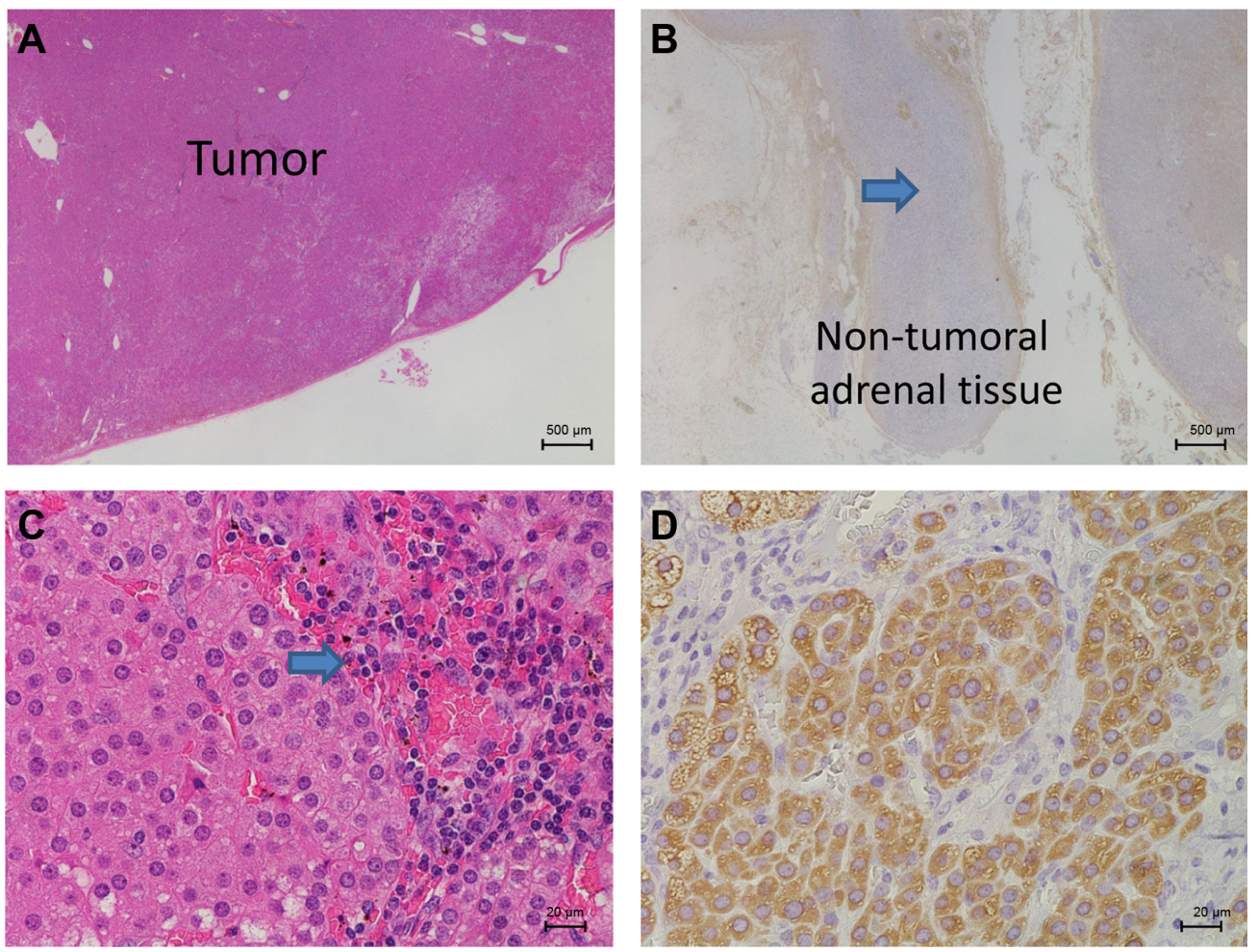

Figure 3 Histological findings of the resected left adrenal gland.

Notes: (A) Tissue sections stained with hematoxylin and eosin (HE) (20x) demonstrated an apparently marginated encapsulated tumor without any capsular or blood vessel invasion. (B) The zona reticularis and fasciculata of the attached non-tumoral adrenal tissue was atrophic (arrow) and showed little expression of dehydroepiandrosterone sulfate $(20 \times)$. (C) The tumor consisted mainly of compact cells and partially of clear cells (HE, 400x). A slight infiltration of lymphocytes (arrow) was observed in the tumor. (D) Most of the tumor cells indicated positive immunostaining for 1 $7 \alpha$-hydoroxylase $(400 \times)$.

The patient is being followed up in the outpatient clinic, and his subsequent clinical course has been uneventful.

\section{Discussion}

We described an adolescent Japanese patient with cognitive impairment and brain atrophy associated with Cushing's syndrome, whose brain volume and cognitive function recovered rapidly after treatment of hypercortisolemia by removing cortisol-secreting adrenal adenoma.

Brain atrophy can occur in a wide variety of conditions other than aging, and notable causes include exogenous or endogenous steroids, chronic alcohol ingestion, radiation therapy, or anorexia nervosa. ${ }^{5-7,15}$ None of the conditions other than excessive endogenous steroid hormones was present in our patient. Therefore, it is plausible that diffuse brain atrophy was caused by endogenous Cushing's syndrome in our case.

The patient exhibited decreased brain volume in the cerebral and cerebellar hemispheres, including the hippocampus, along with dilatation of the ventricles, subarachnoid space, and sulci on MRI. These morphological brain changes were consistent with previously reported changes in patients with endogenous Cushing's syndrome. ${ }^{9,15}$
The prognosis of central nervous system alterations caused by endogenous Cushing's syndrome has been suggested to differ between adults and children. Studies of successfully treated adults with Cushing's syndrome showed no change or only partial amelioration of cognitive impairment within 1 year $^{16-19}$ and partial reversal of brain atrophy with follow-up over several years. ${ }^{20-22}$ In contrast, a study of eleven children under the age of 16 years with Cushing's syndrome with a mean duration of 4.4 years showed almost complete reversal of brain atrophy but a subsequent decline in cognitive function during the 1 year following correction of hypercortisolemia. ${ }^{8}$ In the present case, an adolescent patient with a 1-year duration of Cushing's syndrome experienced the reversal of cognitive dysfunction and brain atrophy within approximately 6 months following successful surgical treatment of hypercortisolemia. In addition, the patient presented no recurrent cognitive alterations during approximately 3 years post-surgery. These findings suggest that the young age at onset and the short duration of Cushing's syndrome probably contributed to the rapid reversibility of both cognitive dysfunction and brain atrophy in our case. Long-term follow-up is, however, required, especially with regard to cognitive function. 
The pathogenesis of brain atrophy in Cushing's syndrome is thought to be multifactorial, and possible explanations include loss of water content in brain tissue, catabolic effects on proteins, reduction in glucose metabolism, synaptic accumulation of glutamate, or neuronal cell death. ${ }^{6,15}$ The present case did not provide information about the precise mechanisms.

\section{Conclusion}

We reported a case of reversible brain atrophy and cognitive impairment in a patient with endogenous Cushing's syndrome. The young age at onset and the short duration of Cushing's syndrome may have contributed to the rapid reversibility of both cognitive dysfunction and brain atrophy in our case. The prevalence of brain atrophy in patients with Cushing's syndrome remains unknown. The presence or absence of causal links between brain atrophy and cognitive impairment in chronic hypercortisolemia is also unclear. However, clinicians may consider Cushing's syndrome as a possible causal condition in patients with cognitive impairment and brain atrophy that is atypical for their age.

\section{Acknowledgments}

The authors thank Dr Hiroyuki Usuda (Nagaoka Red Cross Hospital, Japan), Dr Takashi Maekawa, and Dr Hironobu Sasano (Tohoku University, Japan) for their pathology investigation. We also thank Dr Naoyuki Kojima (Niigata Medical Center, Japan) and Dr Kyuzi Kamoi (Joetsu General Hospital, Japan) for their excellent advice.

\section{Disclosure}

The authors declare no conflicts of interest in this work.

\section{References}

1. Newell-Price J, Bertagna X, Grossman AB, Nieman LK. Cushing's syndrome. Lancet. 2006;367(9522):1605-1617.

2. Arnaldi G, Angeli A, Atkinson AB, et al. Diagnosis and complications of Cushing's syndrome: a consensus statement. J Clin Endocrinol Metab. 2003;88(12):5593-5602.

3. Miyachi Y. Pathophysiology and diagnosis of Cushing's syndrome. Biomed Pharmacother. 2000;54 Suppl 1:S113-S117.

4. Sonino N, Fallo F, Fava GA. Psychosomatic aspects of Cushing's syndrome. Rev Endocr Metab Disord. 2010;11(2):95-104.
5. Momose KJ, Kjellberg RN, Kliman B. High incidence of cortical atrophy of the cerebral and cerebellar hemispheres in Cushing's disease. Radiology. 1971;99(2):341-348.

6. Heinz ER, Martinez J, Haenggeli A. Reversibility of cerebral atrophy in anorexia nervosa and Cushing's syndrome. J Comput Assist Tomogr. 1977;1(4):415-418.

7. Bentson J, Reza M, Winter J, Wilson G. Steroids and apparent cerebral atrophy on computed tomography scans. J Comput Assist Tomogr. 1978; 2(1):16-23.

8. Merke DP, Giedd JN, Keil MF, et al. Children experience cognitive decline despite reversal of brain atrophy one year after resolution of Cushing syndrome. J Clin Endocrinol Meta. 2005;90(5):2531-2536.

9. Bourdeau I, Bard C, Forget H, Boulanger Y, Cohen H, Lacroix A. Cognitive function and cerebral assessment in patients who have Cushing's syndrome. Endocrinol Metab Clin North Am. 2005;34(2): 357-369.

10. Resmini E, Santos A, Gómez-Anson B, et al. Verbal and visual memory performance and hippocampal volumes, measured by 3-Tesla magnetic resonance imaging, in patients with Cushing's syndrome. J Clin Endocrinol Metab. 2012;97(2):663-671.

11. Ragnarsson O, Berglund P, Eder DN, Johannsson G. Long-term cognitive impairments and attentional deficits in patients with Cushing's disease and cortisol-producing adrenal adenoma in remission. $J$ Clin Endocrinol Metab. 2012;97(9):E1640-E1648.

12. Lindsay JR, Nansel T, Baid S, Gumowski J, Nieman LK. Longterm impaired quality of life in Cushing's syndrome despite initial improvement after surgical remission. J Clin Endocrinol Metab. 2006;91(2):447-453.

13. Wood-Dauphinee SL, Opzoomer MA, Williams JI, Marchand B, Spitzer WO. Assessment of global function: The Reintegration to Normal Living Index. Arch Phys Med Rehabil. 1988;69(8):583-590.

14. Toma AK, Holl E, Kitchen ND, Watkins LD. Evans' index revisited: the need for an alternative in normal pressure hydrocephalus. Neurosurgery. 2011;68(4):939-944.

15. Simmons NE, Do HM, Lipper MH, Laws ER Jr. Cerebral atrophy in Cushing's disease. Surg Neurol. 2000;53(1):72-76.

16. Martignoni E, Costa A, Sinforiani E, et al. The brain as a target for adrenocortical steroids: cognitive implications. Psychoneuroendocrinology. 1992;17(4):343-354.

17. Mauri M, Sinforiani E, Bono G, et al. Memory impairment in Cushing's disease. Acta Neurol Scand. 1993;87(1):52-55.

18. Forget H, Lacroix A, Cohen H. Persistent cognitive impairment following surgical treatment of Cushing's syndrome. Psychoneuroendocrinology. 2002;27(3):367-383.

19. Dorn LD, Cerrone P. Cognitive function in patients with Cushing syndrome: a longitudinal perspective. Clin Nurs Res. 2000;9(4): $420-440$.

20. Starkman MN, Giordani B, Gebarski SS, Berent S, Schork MA, Schteingart DE. Decrease in cortisol reverses human hippocampal atrophy following treatment of Cushing's disease. Biol Psychiatry. 1999;46(12):1595-1602.

21. Bourdeau I, Bard C, Noël B, et al. Loss of brain volume in endogenous Cushing's syndrome and its reversibility after correction of hypercortisolism. J Clin Endocrinol Metab. 2002;87(5):1949-1954.

22. Gnjidić Z, Sajko T, Kudelić N, et al. Reversible "brain atrophy" in patients with Cushing's disease. Coll Antropol. 2008;32(4):1165-1170.

\section{Publish your work in this journal}

Neuropsychiatric Disease and Treatment is an international, peerreviewed journal of clinical therapeutics and pharmacology focusing on concise rapid reporting of clinical or pre-clinical studies on a range of neuropsychiatric and neurological disorders. This journal is indexed on PubMed Central, the 'PsycINFO' database and CAS,

\section{Dovepress}

and is the official journal of The International Neuropsychiatric Association (INA). The manuscript management system is completely online and includes a very quick and fair peer-review system, which is all easy to use. Visit http://www.dovepress.com/testimonials.php to read real quotes from published authors. 